Provided for non-commercial research and education use. Not for reproduction, distribution or commercial use.

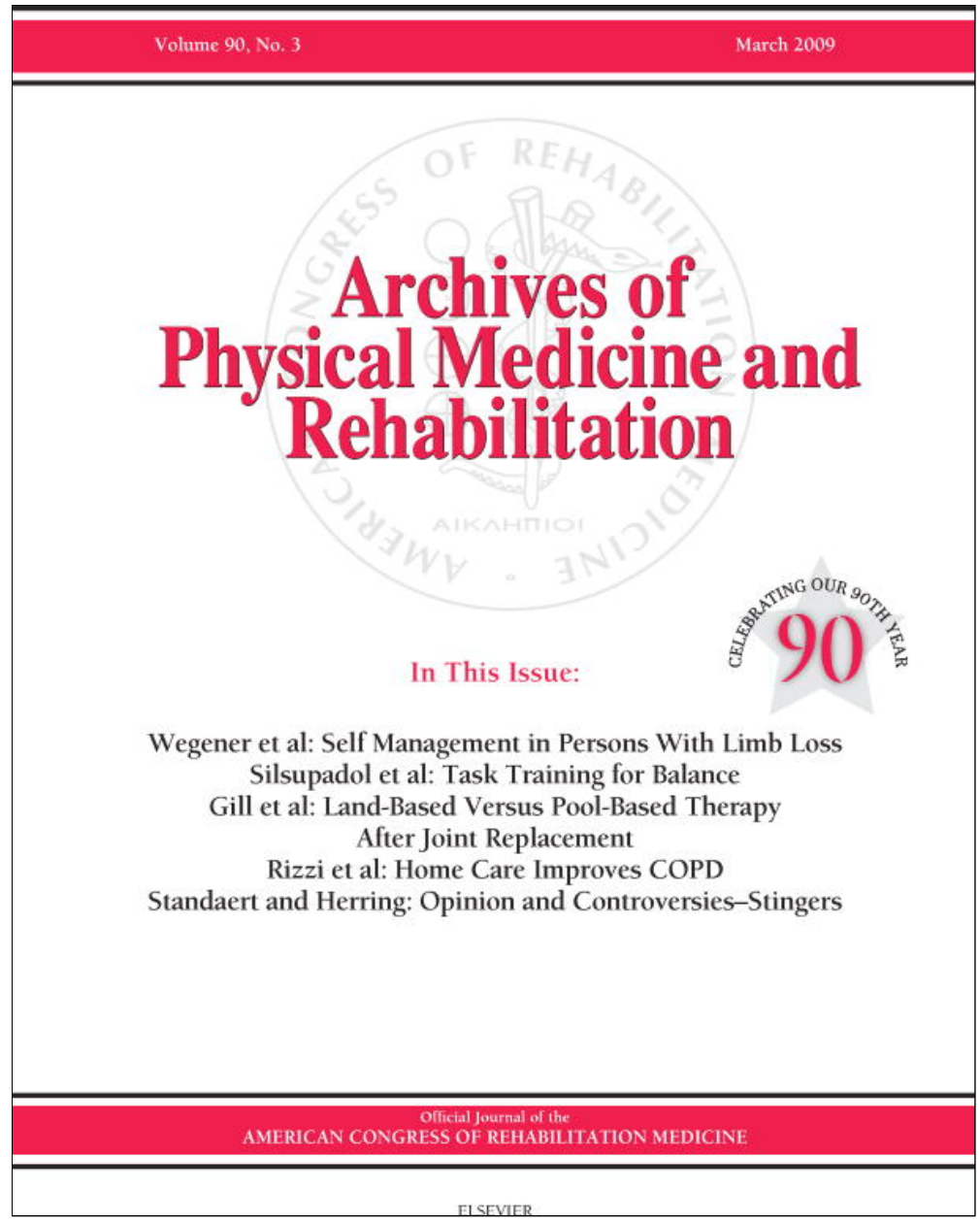

This article appeared in a journal published by Elsevier. The attached copy is furnished to the author for internal non-commercial research and education use, including for instruction at the authors institution and sharing with colleagues.

Other uses, including reproduction and distribution, or selling or licensing copies, or posting to personal, institutional or third party websites are prohibited.

In most cases authors are permitted to post their version of the article (e.g. in Word or Tex form) to their personal website or institutional repository. Authors requiring further information regarding Elsevier's archiving and manuscript policies are encouraged to visit:

http://www.elsevier.com/copyright 


\section{Assistive Walking Devices in Nonambulant Patients Undergoing Rehabilitation After Stroke: The Effects on Functional Mobility, Walking Impairments, and Patients' Opinion}

\section{Sarah F. Tyson, PhD, Louise Rogerson, BSc}

ABSTRACT. Tyson SF, Rogerson L. Assistive walking devices in nonambulant patients undergoing rehabilitation after stroke: the effects on functional mobility, walking impairments, and patients' opinion. Arch Phys Med Rehabil 2009;90:475-9.

Objective: To assess the immediate effects of assistive walking devices on functional mobility, walking impairments, and patients' opinions in nonambulant patients after stroke.

Design: Randomized crossover trial.

Setting: Inpatient rehabilitation units of 3 United Kingdom hospitals.

Participants: Twenty nonambulant patients with stroke undergoing rehabilitation to restore walking.

Interventions: Five walking conditions: (1) Walking with no device (the control condition), (2) walking with a walking cane, (3) ankle foot orthosis, (4) slider shoe, and (5) a combination of all 3 devices.

Main Outcome Measures: Functional mobility (functional ambulation categories), walking impairments (speed, step length of the weak leg), and patients' opinions.

Results: Functional mobility improved with all assistive devices $(P<.0001-.005$; effect sizes 1.68-0.52; number needed to treat $=2-5$ ). Walking impairments were unchanged $(P<.800-.988)$. Participants were generally positive about the devices. They felt their walking, confidence, and safety improved and found the appearance and comfort of the devices acceptable. They would rather walk with the devices than delay walking until a normative gait pattern was achieved without them.

Conclusions: Assistive walking devices improved functional mobility in nonambulant rehabilitation patients with stroke. No changes in walking impairments were found. Participants were generally positive about using the devices. The results support the use of assistive walking devices to enable early mobilization after stroke; 2 patients would need to be treated with a cane or combined devices for 1 to improve functional mobility.

From the Centre for Rehabilitation and Human Performance Research, University of Salford, Salford, United Kingdom (Tyson), and Manchester Primary Care Trust, Manchester, United Kingdom (Rogerson).

Presented at the 15th World Congress of Physical Therapy, June 2007, Vancouver, British Columbia, Canada; the Society for Research in Rehabilitation Summer Meeting, July 2007, Leeds, United Kingdom; the Physiotherapy Research Society, January 2007, Cardiff, United Kingdom; and the United Kingdom Stroke Forum, December 2006, Harrogate, United Kingdom.

Supported by the Physiotherapy Department of Pennine Acute National Health Service Trust, the Association of Chartered Physiotherapists in Neurology, the Physiotherapy Research Society, and donations of the ankle foot orthoses from Halo Medical and Medistock.

No commercial party having a direct financial interest in the results of the research supporting this article has or will confer a benefit on the authors or on any organization with which the authors are associated.

Reprint requests to Sarah F. Tyson, PhD, Centre for Rehabilitation and Human Performance Research, Frederick Rd Campus, University of Salford, Salford, M6 6PU, United Kingdom, e-mail: s.tyson@salford.ac.uk.

0003-9993/09/9003-00445\$36.00/0

doi:10.1016/j.apmr.2008.09.563
Key Words: Ankle; Canes; Foot; Orthotic devices; Patient satisfaction; Rehabilitation; Shoes; Stroke; Walking.

(C) 2009 by the American Congress of Rehabilitation Medicine

$\mathbf{R}$ ESTORATION OF WALKING is a primary goal for people with stroke and their therapists, ${ }^{1,2}$ and most stroke survivors regain the ability to walk. ${ }^{3}$ However, this encouraging statement belies significant activity restriction; hemiplegic gait is slow and energy-inefficient, ${ }^{4}$ few people with stroke are able to mobilize outside the house as they wish, and approximately $20 \%$ are unable to get out of the house unaided at all. ${ }^{5}$ One way to manage walking disability after stroke is to use assistive devices such as a walking cane or AFO. These are popular with patients; more than two thirds of people with stroke use a walking cane, ${ }^{6}$ and more than $20 \%$ use an AFO, ${ }^{7}$ but they are controversial with physiotherapists. In the United Kingdom, physiotherapists are traditionally reluctant to use assistive devices because they believe they limit the restoration of normative walking patterns and independent mobility. ${ }^{8-10}$ More recently, physiotherapists perceive that their practice has evolved to embrace the use of assistive devices, ${ }^{11-13}$ but this is not evident in actual day-to-day clinical practice. ${ }^{14}$

There is a growing body of evidence that shows assistive devices, particularly AFOs, may have a beneficial effect on walking in people with stroke. ${ }^{15-25}$ However, evidence has focused on people with chronic stroke who have completed their rehabilitation and the effects on walking impairments. Other important issues such as the effects on walking activity, people who are undergoing rehabilitation, assistive devices other than AFOs, and patients' opinions and satisfaction have been relatively neglected. We aimed to address these issues by investigating the effect of assistive walking devices on functional mobility, walking impairments, and patients' opinions in nonambulant patients undergoing rehabilitation after stroke.

\section{METHODS}

\section{Participants}

Participants were recruited from 3 National Health Service trusts in Manchester, United Kingdom. We aimed to recruit patients in a very specific period during their rehabilitation: people who were just getting up on their feet to start walking but were unable to walk functionally in everyday life. Thus the inclusion criteria were the following:

- Unable to walk for at least 2 weeks after their stroke

- Undergoing inpatient rehabilitation to restore walking

List of Abbreviations

AFO ankle foot orthosis
FAC functional ambulation category


- Unable to mobilize independently without aids in everyday life on the ward

- Able to step and practice walking during physiotherapy sessions although they may need support

- Able to walk $5 \mathrm{~m}$ without physical support (the minimum walking distance for the test procedure)

- Able to give informed consent

Patients' progress was screened by the treating physiotherapist, and when they achieved the inclusion criteria, the physiotherapist approached the patient to take part in the study. If they agreed, the research physiotherapist (L.R.) was contacted, and an appointment for testing was made. Power calculations were made on unpublished data from a previous study of the effects of an AFO on nonambulant people undergoing rehabilitation. ${ }^{15}$ Sixteen participants would give $95 \%$ power with a $5 \%$ level of significance with a mean difference of $0.071 \mathrm{~m} / \mathrm{s}$ $(\mathrm{SD}=0.783)$ between walking with and without an AFO. The sample size was rounded up to 20 to allow for dropouts. Ethical approval for the study was obtained from University of Salford and local research ethics committees for each of the participating National Health Service trusts.

Twenty patients were recruited, and all completed testing with no dropouts. None were using the assistive devices as part of their rehabilitation. Mean age was 65.6 years $(S D=10.4)$, and the mean time since stroke was 6.5 weeks $(\mathrm{SD}=5.7)$. Seven had a right hemiparesis, and 13 had a left hemiparesis. They were a severely impaired group; mean Motricity Index score was 48/100 ( $\mathrm{SD}=17.5)$, mean Rivermead Assessment of Somatosensory Perception score was $6.7 / 18(\mathrm{SD}=0.7)$, and mean Brunel Balance Assessment score was 6.4/12 $(\mathrm{SD}=1.1)$. In their daily physiotherapy sessions, the treating physiotherapists categorized their walking activity as follows: $10(50 \%)$ were unable to walk without assistive devices, $8(40 \%)$ needed constant support, and $2(10 \%)$ were able to walk with intermittent support. The median FAC was 1 (walking with constant support; interquartile range, 1,1).

\section{Design and Procedure}

A randomized controlled crossover trial was undertaken. The patients' walking with no assistive device was the control condition, and walking with each of the assistive devices was the intervention. The order in which the different conditions were tested was randomized, and allocation was concealed. After consent and the initial descriptive information had been obtained, the patient picked a concealed envelope containing the randomized testing order from a bag. Neither the tester nor patient could be blind to the testing order because it is obvious whether someone is using an assistive device. To negate the effects of rehabilitation or spontaneous recovery, all testing was performed in a single day.

\section{Assistive Devices}

The assistive devices used were those most commonly used in clinical practice: a walking cane, an AFO, and a slider shoe. The walking cane was a standard issue, adjustable metal walking cane. Its length was adjusted for each patient so that the handle was level with the greater trochanter of the patient's sound hip; it was held in the sound hand. The AFO was an Ossur leaf spring ankle foot orthosis ${ }^{\mathrm{a}}$ (http://www.ossur.com), which is an off-the-shelf AFO used as a standard issue orthosis in many hospitals in the United Kingdom. The AFO was individually fitted for each patient. The slider shoe was a custom-made half-shoe of thermo-moldable plastic that fits over the subject's own shoe and is secured by a raised lip around the toe and sides and an elastic strap around the heel. It enables the patient to slide their weak foot forward to make a step when they are too weak to lift their foot off the ground to advance the leg.

\section{Measurements and Outcome Measures}

The descriptive information gathered was age, sex, time since stroke, side of hemiparesis, weakness of the lower limb (Motricity Index ${ }^{26}$ ), sensation of the lower limb (Rivermead Assessment of Somatosensory Perception ${ }^{27}$ ), and balance (Brunel Balance Assessment ${ }^{28}$ ).

The descriptive information was gathered and the assistive devices were fitted in the morning, during which time the patients had opportunity to practice with the devices as much as they wished. Testing took place in the afternoon. The primary outcome, functional mobility, was measured using the FAC, a reliable, valid 6-point ordinal scale of the independence of walking. ${ }^{29,30}$ Items range from being unable to walk through dependence on support or supervision from another person, to independence walking on level ground, and finally independence to walk anywhere. The walking impairments were walking speed and step length of the weak leg under each testing condition, measured using a five-meter walk test. ${ }^{31}$ The fivemeter walk test was repeated twice for each condition and mean values calculated. To perform this, a 5-m distance was marked on the floor and the time and number of steps taken for the participant to walk the $5 \mathrm{~m}$ measured. The participant started to walk a meter before the start line and continued at a self-selected pace until they crossed the finish line, so they walked at their normative speed over the full $5 \mathrm{~m}$. They rested as they felt necessary during the testing session. The amount of practice was not recorded. Five meters was chosen as the distance for the timed walk test because of the severe impairments experienced by the target population; previous experience indicated that they would not be able to walk the $10 \mathrm{~m}$ commonly used as a walk test for more able populations and has found the five-meter walk test to be reliable, valid, and able to detect changes from using assistive devices in this patient group. ${ }^{15,23,31}$ Walking speed was calculated from the time taken to walk $5 \mathrm{~m}$ (5/time [seconds]), and mean step length was calculated from the number of steps taken with the weak leg (5/number of steps).

After the gait testing was complete, the participants filled in a written questionnaire on their opinions about each device. The questionnaire was adapted from one previously used by the authors to investigate opinions of AFOs. ${ }^{15}$ It consisted of open and closed questions and Likert scales asking about the effect of the device on the participants' gait, their views of the device itself and using them to enable early mobilization, and their preferences.

\section{Analysis}

Differences between each of the 4 assistive devices and the control condition (walking with no device) were assessed using the Friedman test for the categorical data (the FAC and questionnaire) and a 1-way ANOVA for continuous data (the measures of walking impairment). Where significant differences were found, Mann-Whitney $U$ tests and paired $t$ tests were used to identify where they lay, and then the effect size ([mean treatment $_{-}$ mean $\left._{\text {control }}\right] / \mathrm{SD}$ ), percentage change, and numbers needed to treat were calculated.

\section{RESULTS}

When the patients walked with each of the devices, and all the devices combined, there was a significant improvement in functional mobility compared with walking with no device 
Table 1: The Median (IQR) Values for the Functional Ambulation Categories Under Each Walking Condition and the $P$ Values, Effect Sizes, and Numbers Needed to Treat for Comparison With Walking With No Device

\begin{tabular}{lcccc}
\hline & $\begin{array}{c}\text { Median } \\
(\text { IQR) }\end{array}$ & $\begin{array}{c}\text { Comparison With } \\
\text { Walking With No } \\
\text { Aid }(P \text { Value })\end{array}$ & $\begin{array}{c}\text { Effect Size } \\
(\% \text { Change) }\end{array}$ & $\begin{array}{c}\text { NNT } \\
(95 \% \mathrm{Cl})\end{array}$ \\
\hline $\begin{array}{l}\text { No device } \\
\text { (control) }\end{array}$ & $1(1-1)$ & & & \\
Walking cane & $2(2-2)$ & .0001 & $1.68(64)$ & $2(1.1-1.6)$ \\
AFO & $2(1-2)$ & .0001 & $1.04(44)$ & $3(1.7-3.7)$ \\
Slider shoe & $1(1-2)$ & .005 & $0.52(18)$ & $5(3-1,13.2)$ \\
All devices & $2(2-2)$ & .0001 & $1.65(68)$ & $2(1.1-1.6)$ \\
\hline
\end{tabular}

Abbreviations: IQR, interquartile range; NNT, number needed to treat.

$(P=.000)$. The Mann-Whitney tests showed significant improvements in FAC with all the devices compared with the control (table 1). The effect size was very high for the walking cane, AFO, and combined devices (effect size $=1.04-1.68$ ) and was moderate for the slider shoe (effect size $=0.52$ ). The numbers needed to treat ranged from 2 (for the walking cane and for all devices) to 5 (for the slider shoe). The walking impairments showed no significant differences with any of the devices compared with the control. For walking speed, the $P$ value was 0.935 and for step length of the weak leg, it was 0.998. Mean and SD values are shown in table 2 .

The participants' responses to questions about the effects of the assistive devices are shown in table 3 . They were generally positive about the devices; few felt that any of the devices had a negative effect. Although they tended to be less positive about the slider shoe than the walking cane or AFO, there were no differences in the participants' opinions about the effects of the devices on their gait except for the effect on safety while walking, in which the slider shoe scored less well than the other devices.

The participants' responses to questions about the devices are shown in table 4 . They found the devices comfortable, and most did not find the appearance of the devices off-putting. Of those who did, only 2 (10\% of the whole group) felt that the appearance would stop them from using the device. When asked whether they would prefer a wooden or metal walking cane, $8(40 \%)$ chose a wooden one, $11(55 \%)$ chose a metal one, and 1 did not have a preference. When asked whether they would choose any of the aids to use on a regular basis, 19 $(95 \%)$ answered yes, $7(35 \%)$ would choose a cane, $6(30 \%)$ would choose a cane and an AFO combined, 2 (10\%) would choose an AFO, $1(5 \%)$ would choose a slider shoe, $1(5 \%)$ would choose a slider shoe and a walking cane combined, and $3(15 \%)$ did not have a preference. When asked whether participants would rather walk now using an assistive device or delay walking and learn to walk with a normative gait pattern without a device, $14(70 \%)$ chose to walk immediately with an

Table 2: The Mean (SD) Values for Walking Impairments Under Each Experimental Condition

\begin{tabular}{|c|c|c|}
\hline & Speed $(\mathrm{m} / \mathrm{s})$ & Weak Step Length (m) \\
\hline No device (control) & $0.3(0.14)$ & $0.53(0.16)$ \\
\hline Walking cane & $0.28(0.15)$ & $0.51(0.17)$ \\
\hline AFO & $0.30(0.12)$ & $0.53(0.15)$ \\
\hline Slider shoe & $0.31(0.13)$ & $0.52(0.16)$ \\
\hline All devices & $0.29(0.14)$ & $0.52(0.18)$ \\
\hline
\end{tabular}

Table 3: Participants' Responses to the Questionnaire About the Effect of an Assistive Device on Their Gait; They Were Asked, "Did the Device Change Your..."

\begin{tabular}{|c|c|c|c|}
\hline & $\begin{array}{c}\text { Better \% } \\
(\mathrm{n} / \mathrm{N})\end{array}$ & $\begin{array}{c}\text { The Same } \\
\%(n / N)\end{array}$ & $\begin{array}{c}\text { Worse \% } \\
(\mathrm{n} / \mathrm{N})\end{array}$ \\
\hline \multicolumn{4}{|c|}{$\begin{array}{l}\text { Ability to take weight on your } \\
\text { weak leg }(P<.012)\end{array}$} \\
\hline Cane & $65(13 / 20)$ & $35(7 / 20)$ & $0(0)$ \\
\hline AFO & $45(9 / 20)$ & $40(8 / 20)$ & $15(3 / 20)$ \\
\hline Slider shoe & $10(2 / 20)$ & $80(16 / 20)$ & $10(2 / 20)$ \\
\hline All 3 devices & $55(11 / 20)$ & $30(6 / 20)$ & $5(1 / 20)$ \\
\hline \multicolumn{4}{|c|}{$\begin{array}{l}\text { Ability to move your weak leg } \\
\quad \text { forward }(P<.332)\end{array}$} \\
\hline Cane & $45(9 / 20)$ & $50(10 / 20)$ & $5(1 / 20)$ \\
\hline AFO & $40(8 / 20)$ & $35(7 / 20)$ & $25(5 / 20)$ \\
\hline Slider shoe & $30(6 / 20)$ & $60(12 / 20)$ & $10(2 / 20)$ \\
\hline All 3 devices & $55(11 / 20)$ & $40(8 / 20)$ & $5(1 / 20)$ \\
\hline \multicolumn{4}{|c|}{$\begin{array}{l}\text { Confidence when walking } \\
\qquad(P<.058)\end{array}$} \\
\hline Cane & $55(11 / 20)$ & $35(7 / 20)$ & $10(2 / 20)$ \\
\hline AFO & $55(11 / 20)$ & $30(6 / 20)$ & $15(3 / 20)$ \\
\hline Slider shoe & $5(1 / 20)$ & $80(16 / 20)$ & $15(3 / 20)$ \\
\hline All 3 devices & $50(10 / 20)$ & $45(9 / 20)$ & $5(1 / 20)$ \\
\hline \multicolumn{4}{|c|}{ Safety when walking $(P<.008)$} \\
\hline Cane & $50(10 / 20)$ & $40(8 / 20)$ & $10(2 / 20)$ \\
\hline AFO & $40(8 / 20)$ & $45(9 / 20)$ & $15(3 / 20)$ \\
\hline Slider shoe & $5(1 / 20)$ & $80(16 / 20)$ & $15(3 / 20)$ \\
\hline All 3 devices & $55(11 / 20)$ & $40(8 / 20)$ & $5(1 / 20)$ \\
\hline \multicolumn{4}{|c|}{ Walking style (limp) $(P<.627)$} \\
\hline Cane & $45(9 / 20)$ & $35(7 / 20)$ & $20(4 / 20)$ \\
\hline AFO & $40(8 / 20)$ & $30(6 / 20)$ & $30(6 / 20)$ \\
\hline Slider shoe & $20(4 / 20)$ & $60(12 / 20)$ & $20(4 / 20)$ \\
\hline All 3 devices & $25(5 / 20)$ & $60(12 / 20)$ & $15(3 / 20)$ \\
\hline
\end{tabular}

assistive device, and only $3(15 \%)$ would rather delay walking until they could walk without a device. One participant could not make a choice, and 2 did not answer.

\section{DISCUSSION}

The results of this study show that using assistive devices can produce an immediate improvement in functional mobility in nonambulant people with stroke but does not affect walking impairments; the long-term effects of using an assistive device in everyday life have not been investigated. The numbers needed to treat indicate that 1 in 2 patients will show an improvement in their functional mobility when they use a walking cane or all 3 devices combined. There have been only 2 previous studies assessing the effects of assistive walking

Table 4: Participants' Responding Yes to Questions About the Assistive Devices

\begin{tabular}{|c|c|c|c|}
\hline & Cane $\%(n / N)$ & AFO $\%(n / N)$ & $\begin{array}{l}\text { Slider Shoe \% } \\
(n / N)\end{array}$ \\
\hline \multicolumn{4}{|l|}{$\begin{array}{r}\text { Was the device } \\
\text { comfortable? }\end{array}$} \\
\hline$(P<.165)$ & $85(17 / 20)$ & $85(17 / 20)$ & $100(20 / 20)$ \\
\hline \multicolumn{4}{|l|}{$\begin{array}{l}\text { Was the appearance } \\
\text { off-putting? }\end{array}$} \\
\hline$(P<.529)$ & $20(4 / 20)$ & $15(3 / 20)$ & $20(5 / 20)$ \\
\hline $\begin{array}{l}\text { If yes, would it stop } \\
\text { you using it? }\end{array}$ & $\begin{array}{c}10 \% \text { of whole } \\
\text { group }(2 / 4)\end{array}$ & $\begin{array}{c}10 \% \text { of whole } \\
\text { group }(2 / 4)\end{array}$ & $\begin{array}{r}10 \% \text { of whole } \\
\text { group }(2 / 4)\end{array}$ \\
\hline
\end{tabular}


devices on functional mobility, ${ }^{15,16}$ both of which studied AFOs and also showed a significant benefit when using the AFO, but neither reported the effect sizes nor numbers needed to treat. To the authors' knowledge, no previous studies have assessed the effect of a walking cane, slider shoe, or combination of assistive walking devices on functional mobility.

The results of this study also show that participants' immediate responses to the assistive walking devices were positive; they felt they improved their walking, confidence, and safety. The appearance did not put them off using the devices; they found them comfortable and would like to use them in everyday life. They would also rather start to walk with the devices than delay walking until they can walk with a normative gait pattern without them. They tended to be more positive about the walking cane and AFO than the slider shoe, but the only significant difference was in the perceived effect on their safety while walking, in which the slider shoe scored less well than the walking cane and AFO. To the authors' knowledge, this is the first study that has reported users' opinions of a walking cane and slider shoe, so comparisons cannot be made. There have been 3 studies that considered the participants' opinions of AFOs, ${ }^{15,16,20}$ and the results of the present study are comparable to these. Hesse et $\mathrm{al}^{20}$ reported participants' subjective impression of a metal Valens AFO that had been worn for less than a week by patients undergoing rehabilitation; participants all felt they walked better with the AFO than without; 5 (25\%) found it unpleasantly heavy, and $2(20 \%)$ had reservations about the appearance. de Wit et $\mathrm{al}^{16}$ asked participants to use 5 -point Likert scales to rate the effect of an off-the-shelf plastic AFO (which had been worn daily for at least 6 months) on self-confidence and the difficulty to perform functional tasks (walking, standing up, sitting down, and stairs). They found $65 \%$ reported less difficulty and $70 \%$ reported greater selfconfidence, differences that were considered clinically significant. Tyson and Thornton ${ }^{15}$ used an earlier version of the questionnaire used in the present study to explore opinions of a custom-made hinged AFO used for at least a week by patients undergoing rehabilitation. As in the present study, patients felt the AFO improved their walking, reservations about the appearance were outweighed by the benefits found, and they would rather walk sooner with the devices than delay functional walking until they could walk without them.

The results of the present study have important clinical implications. They refute the belief held by many physiotherapists that patients with stroke do not want to use assistive devices and that their priority is to obtain a normative-looking gait without aids, rather than to regain functional mobility even in an adapted fashion. ${ }^{11}$ They also support previous studies showing assistive devices can improve mobility when used during rehabilitation. ${ }^{23-25,32,33}$ This suggests that assistive devices should be considered to enable patients with stroke to mobilize as soon as they are safely able to do so during stroke rehabilitation, rather than attempting to restore walking without devices as an initial and primary goal and using assistive devices only as a last resort.

\section{Study Limitations}

Although the results of the present study are encouraging, they are limited to the immediate effects on walking activity. Having established that assistive devices can have a beneficial effect, a phase II pragmatic trial of the long-term effectiveness of using assistive devices to promote early mobilization is needed. This will establish whether the effects on mobility and patients' views seen in this study are maintained once they are used in everyday life and the initial novelty has abated. If using assistive devices can enable patients to mobilize in everyday life on the ward earlier than is current practice, then there is potential to reduce the length of stay with considerable cost savings. Such a study would also need to investigate adverse events such as pain, falls, or an increase in spasticity and adherence to usage of the devices. The long-term effects on mobility, patients' satisfaction, mood and well being, and an economic evaluation should also be considered.

The lack of effect on walking impairments contrasts with previous studies that have shown improved walking speed and step length of the weak leg in patients undergoing rehabilitation. ${ }^{15,19-21}$ There has been only 1 previous publication investigating the effects of a slider shoe, ${ }^{23}$ a single case design of 4 patients undergoing rehabilitation, all of whom showed improvements in walking speed while using the slider shoe. Previous studies of the effects of walking aids have focused on the effects on gait kinematics, muscle activity, and balance. $^{24,25,32-38}$ The results have been mixed, but improvements in walking speed, step length, and muscle activity have been reported. ${ }^{2,32,33}$ The present study involves a similar participant group, outcome measures, and study design to these previous studies, but we think a crucial difference, which could explain the contrasting results, was the familiarization period when the patients used the assistive devices before testing. The need to avoid the confounding effects of rehabilitation or spontaneous recovery, which would have occurred if a longitudinal design had been used, meant that the devices needed to be fitted and tested within 1 day. As a consequence, the participants had only a short time to become familiar with the devices and to adapt their walking pattern. Because the participants' walking was severely impaired and therefore energy demanding, their capacity to practice before testing was limited. This was not an unreasonable strategy because previous studies have involved a minimal familiarization period but found positive results. ${ }^{16,18,23-25}$ However, they involved more able patients, mostly with chronic stroke, and tested only 1 device at a time. More able patients and those with chronic stroke may have been more able to adapt their gait pattern within a short period. Participants in previous studies of patients undergoing rehabilitation $^{15,19-21}$ (all investigated AFOs) wore their AFO in dayto-day life for at least a week before testing. This may have been a better design; however, it would have required the treating physiotherapists to agree to let their patients wear and use assistive devices. Because the treating physiotherapists in the present study did not normally prescribe assistive devices for their rehabilitation patients and some were hostile to the idea, this had been rejected while planning the study. We felt it would prejudice recruitment rates. In hindsight we do not feel the patients had enough practice to adapt their walking pattern when using the devices, particularly because the inability to adapt to changing conditions is a feature of unskilled movement. Future studies should include an adequate familiarization period when the device is worn in everyday life before testing. A related explanation for the lack of effect on walking impairments is that the sample size was inadequate for the high interindividual and intraindividual variability found in the recruited participants. Our sample size calculation was based on a previous study into the effects of an AFO during rehabilitation involving similar participants and design undertaken by the authors, ${ }^{15}$ but the participants in the earlier study used the AFO in daily life for at least a week before testing. They were also younger and had a hemiplegia of longer duration, which may also have made them more able to adapt their walking pattern. In hindsight, our lack of appreciation of the importance of a familiarization period meant the present study was underpowered. Future studies in which a familiarization period is not possible would need a much larger sample size. 


\section{CONCLUSIONS}

Assistive walking devices can, in the short-term, improve walking activity in nonambulant patients with stroke who are undergoing rehabilitation. No significant effects on walking impairments were found. Participants were generally positive about using the devices. They felt they improved their walking, confidence, and safety. The appearance did not put them off; they found them comfortable and would like to use them in everyday life. They would also rather start to walk with the devices than delay walking until a normative gait pattern is achieved without them. These results support the use of assistive walking devices to enable early mobilization after stroke. They indicate that 2 patients would need to be treated using a walking cane or combined walking devices for 1 person to improve functional mobility.

\section{References}

1. Bohannon RW, Andrews AW, Smith MB. Rehabilitation goals of patients with hemiplegia. Int J Rehabil Res 1988;11:181-3.

2. Ballinger C, Ashburn A, Low J, Roderick P. Unpacking the black box of therapy - a pilot study to describe occupational therapy and physiotherapy interventions for people with stroke. Clin Rehabil 1999;13:301-9.

3. Jorgenson HS, Nakayama H, Raaschou H, Olsen T. Recovery of walking function in stroke patients; The Copenhagen Study. Arch Phys Med Rehabil 1995;76:27-32.

4. Olney S, Monga T, Costigan P. Mechanical energy of walking of stroke patients. Arch Phys Med Rehabil 1986;67:92-8.

5. Lord SE, McPherson K, McNaughton HK, Rochester L, Weatherall M. Community ambulation after stroke: how important and obtainable is it and what measures appear predictive? Arch Phys Med Rehabil 2004;85:234-9.

6. Chin PJ, Rosie A, Irving M, Smith R. Studies in hemiplegic gait. In Rose FC, editor. Advances in stroke therapy. New York: Raven Press; 1982.

7. Teasell RW, McRae MP, Foley N, Bhardwaj A. Physical and functional correlations of ankle-foot orthosis use in the rehabilitation of stroke patients. Arch Phys Med Rehabil 2001;82:1047-9.

8. Davidson I, Waters K. Physiotherapists working with stroke patients: a national survey. Physiotherapy 2000;86:69-80.

9. Lennon S, Baxter D, Ashburn A. Physiotherapy based on the Bobath concept in stroke rehabilitation: a survey within the UK. Disabil Rehabil 2001;23:254-62.

10. Sackley C, Lincoln N. Physiotherapy treatment for stroke: a survey of current practice. Phys Theory Pract 1996;12:87-96.

11. Lennon S, Ashburn A. The Bobath concept in stroke rehabilitation: a focus group study of the experienced physiotherapists' perspective. Disabil Rehabil 2000;22:665-74.

12. Raine S. The current theoretical assumptions of the Bobath concept as determined by the members of BBTA. Phys Theory Pract 2007;23:137-52.

13. Raine S. Defining the Bobath concept using the Delphi technique. Phys Res Int 2006;11:4-13.

14. Tyson S, Selley A. A content analysis of physiotherapy for postural control in people with stroke: an observational study. Disabil Rehabil 2006;28:865-72.

15. Tyson SF, Thornton HM. The effects of a hinged ankle-foot orthosis in hemiplegic gait: objective measures and users' opinion. Clin Rehabil 2001;15:53-8.

16. de Wit DC, Buurke JH, Nijlant JM, IJzerman MJ, Hermens HJ. The effect of an ankle-foot orthosis on walking ability in chronic stroke patients: a randomized controlled trial. Clin Rehabil 2004; 18:550-7.
17. Thijssen DH, Paulus R, van Uden CJ, et al. Decreased energy cost and improved gait pattern using a new orthosis in persons with long-term stroke. Arch Phys Med Rehabil 2007;88:181-6.

18. Danielsson A, Sunnerhagen KS. Energy expenditure in stroke subjects walking with a carbon composite ankle foot orthosis. J Rehabil Med 2004;36:165-8.

19. Hesse S, Werner C, Matthias K, Stephen K, Berteanu M. Nonvelocity-related effects of a rigid double-stopped ankle-foot orthosis on gait and lower limb muscle activity of hemiparetic subjects with an equinovarus deformity. Stroke 1999;30:1855-61.

20. Hesse S, Luecke D, Jahnke MT, Mauritz KH. Gait function in spastic hemiparetic patients walking barefoot, with firm shoes, and with ankle-foot orthosis. Int J Rehabil Res 1996;19:133-41.

21. Gok H, Kucukdeveci A, Altinkaynak H, Yavuzer G, Ergin S. Effects of ankle-foot orthoses on hemiparetic gait. Clin Rehabil 2003; 17:137-9.

22. Royal College of Physicians. National clinical guidelines for stroke. 2nd ed. London: RCP; 2004.

23. Cross J, Tyson S. The effects of a slider shoe on hemiplegic gait. Clin Rehabil 2003;17:817-22.

24. Tyson SF, Ashburn A. The influence of walking aids on hemiplegic gait. Phys Theory Pract 1994;10:77-86.

25. Hesse S, Jahnke MT, Schaffrin A, Lucke D, Reiter F, Konrad M. Immediate effects of therapeutic facilitation on the gait of hemiparetic patients as compared with walking with and without a cane. Electroenceph Clin Neurophys 1998;109:515-22.

26. Demeurrisse G, Demol O, Robaye E. Motor evaluation in vascular hemiplegia. Eur Neurol 1980;19:382-9.

27. Winward CE, Halligan PW, Wade DT. The Rivermead Assessment of Somatosensory Performance (RASP): standardisation and reliability data. Clin Rehabil 2002;16:523-3.

28. Tyson S, DeSouza L. Development of the Brunel Balance Assessment: a new measure of balance disability post-stroke. Clin Rehabil 2004;18:801-10.

29. Holden MK, Gill KM, Magliozzi MR. Gait assessment for neurologically impaired patients—standards for outcome assessment. Phys Ther 1986;66:1530-9.

30. Holden MK, Gill KM, Magliozzi MR, Nathan J, Piehl-Baker L. Clinical gait assessment in the neurologically impairedreliability and meaningfulness. Phys Ther 1984;64:35-40.

31. Tyson S, DeSouza L. Reliability and validity of functional balance tests post-stroke. Clin Rehabil 2004;18:916-23.

32. Kuan TS, Tsou JY, Su F-C. Hemiplegic gait of stroke patients: the effects of using a cane. Arch Phys Med Rehabil 1999;80:777-84.

33. Buurke JH, Hermens HJ, Erren-Wolters CV, Nene AV. The effect of walking aids on muscle activation patterns during walking in stroke patients. Gait Posture 2005;22:164-70.

34. Tyson SF. Trunk kinematics during hemiplegic gait and the effects of walking aids. Clin Rehabil 1999;13:295-300.

35. Tyson SF. The support taken through walking aids during hemiplegic gait. Clin Rehabil 1998;12:395-401.

36. Laufer Y. The effect of walking aids on balance and weightbearing patterns of patients with hemiparesis in various stance positions. Phys Ther 2003;83:112-22.

37. Laufer Y. Effects of one-point and four-point canes on balance and weight distribution in patients with hemiparesis. Clin Rehabil 2002;6:141-8

38. Dickstein R, Abulaffio, Pillar T. Vertical forces loaded on walking canes in hemiparetic patients. Gait Posture 1993;1:113-8.

\section{Supplier}

a. Ossur leaf spring ankle foot orthosis; Ossur, Grjothals 5, 110 Reykjavik, Iceland. 